\title{
Complement Inhibition in Coronavirus Disease (COVID)-19: A Neglected Therapeutic Option
}

\author{
Philip F. Stahel ${ }^{1 *}$ and Scott R. Barnum ${ }^{2}$ \\ ${ }^{1}$ Department of Specialty Medicine, College of Osteopathic Medicine, Rocky Vista University, Parker, CO, United States, \\ ${ }^{2}$ CNine Biosolutions LLC, Birmingham, AL, United States
}

Keywords: COVID-19, coronavirus, hyperinflammation, innate immunity, complement inhibition, pharmacological treatment

\section{INTRODUCTION}

The fatal outcome from coronavirus disease 2019 (COVID-19) is attributed to terminal respiratory failure secondary to bilateral pneumonia from severe acute respiratory syndrome coronavirus2 (SARS-CoV-2) infection (1-3). However, a subset of younger patients with severe COVID-19 suffer from uncontrolled hyperinflammation and succumb to acute organ failure and cardiac arrest while still being adequately oxygenated (4-7). The "cytokine storm" or "cytokine release syndrome" (CRS) has been implicated in adverse patient outcomes, with interleukin-6 (IL-6) representing a key inflammatory mediator and surrogate marker of CRS $(8,9)$. The U.S. Food and Drug Administration (FDA) approved the expanded access to a recombinant monoclonal antibody against human IL-6 receptors (tocilizumab), and a randomized controlled phase 3 clinical trial on tocilizumab in adult patients suffering from severe COVID-19 is currently ongoing (10-13). The available empirical treatment modalities include a wide spectrum of off-label indications for antirheumatic agents, including cytokine inhibitors, corticosteroids, intravenous immunoglobulin, and other novel anti-inflammatory molecules (13-15). However, the exact mechanisms of hyperinflammation and hypercoagulation in COVID-19 patients remain enigmatic and poorly understood.

University of Calfc Ka Man Law,

Cecilia Garlanda,

Humanitas University, Italy

, Los Angeles,

Correspondence:

Philip F. Stahel

Philip.Stahe/@gmail.com

Specialty section:

This article was submitted to Inflammation,

a section of the journal

Frontiers in Immunology

Received: 02 June 2020 Accepted: 22 June 2020

Published: 07 July 2020

Citation:

Stahel PF and Barnum SR (2020) Complement Inhibition in Coronavirus

Disease (COVID)-19: A Neglected

Therapeutic Option.

Front. Immunol. 11:1661.

doi: 10.3389/fimmu.2020.01661

\section{ROLE OF COMPLEMENT IN COVID-19?}

The complement system serves as a "first line of defense" against invading viruses and as a bridge between innate and adaptive immune responses $(16,17)$. Interestingly, complement has received limited attention in the quest for effective anti-inflammatory treatment strategies in spite of multiple intuitive targets in COVID-19, and most of the prevalent anti-inflammatory agents currently under investigation do not include a consideration for complement inhibitors $(8,13,14)$. Complement activation has been previously implicated in the pathophysiology of Middle East respiratory syndrome (MERS) and severe acute respiratory syndrome (SARS) which are severe infectious diseases mediated by coronaviruses that are similar to the pathogen responsible for the current COVID-19 pandemic (SARS-CoV-2). Experimental studies revealed that complement activation occurs in response to SARS-CoV infection, and mice deficient in genes for the central complement component C3 were shown to be protected from pulmonary inflammation and respiratory failure (18). Furthermore, the complement activation fragment anaphylatoxin C5a is a potent mediator of acute lung injury in highly pathogenic viral infections, including MERS and SARS (19). The pharmacological blockade of the C5a receptor (C5aR, CD88) attenuated pulmonary inflammation in a mouse model of MERS-CoV infection, and C5aR blockade led to decreased viral replication in infected lungs (20). In addition, there is an established crosstalk between the 
coagulation cascade and the immune proteolytic system through thrombin- and plasmin-mediated complement activation, and complement activation was recently postulated to induce thrombotic microangiopathy in COVID-19 $(21,22)$. In light of these presumed "key" pathophysiological features mediated by complement activation in response to coronavirus infections, it appears intuitive to consider the pharmacological complement inhibition as part of the "expanded access" paradigm to offlabel indications for anti-inflammatory treatment strategies in COVID-19.

\section{PHARMACOLOGICAL COMPLEMENT INHIBITION}

There are currently multiple pharmacological complement inhibitors available for the treatment of rare inflammatory and autoimmune disorders in humans $(17,23,24)$. Preliminary case reports from "hot zones" in Italy outlined the anecdotal success by compassionate use of the complement C3 inhibitor AMY-101 (Amyndas Pharmaceuticals, Glyfada, Greece) and by administration of the anti-C5 monoclonal antibody eculizumab (Soliris; Alexion, Boston, MA) in the rescue of critically ill COVID-19 patients $(25,26)$. From a mechanistic perspective, AMY-101 inhibits cleavage of C3, the central component in the complement cascade, and thus prevents the formation of the $\mathrm{C} 3$ and $\mathrm{C} 5$ convertases and the subsequent release of the inflammatory mediators $\mathrm{C} 3 \mathrm{a}$ and $\mathrm{C} 5 \mathrm{a}$ and formation of the tissue-damaging membrane attack complex (MAC; C5b9). Further downstream, eculizumab prevents cleavage of C5 and the formation of the inflammatory anaphylatoxin $\mathrm{C} 5 \mathrm{a}$ and of the MAC/C5b-9 (27). Indeed, a recent study from Milan, Italy, reported elevated levels of the C5 activation fragment $\mathrm{C} 5 \mathrm{a}$ and soluble MAC (sC5b-9) in plasma samples of patients with severe COVID-19, confirming the notion that $\mathrm{C} 5$ blockade represents a potentially relevant therapeutic consideration (28). A prospective randomized controlled trial evaluating the safety and efficacy of eculizumab in patients with COVID-19 infection is currently under way ("CORIMUNO19 ” trial). Several additional complement inhibitors are under consideration for compassionate use in COVID-19 (Figure 1). Of these, avdoralimab (Innate Pharma, Marseille, France) is an anti-C5aR monoclonal antibody that prevents binding of C5a to its receptor (C5aR, CD88), while IFX-1 (InflaRX; Martinsried, Germany) is a monoclonal antibody that targets $\mathrm{C} 5 \mathrm{a}$, preventing it from interacting with the C5aR. In addition, the recombinant human $\mathrm{C} 1$ esterase inhibitor conestat alfa (Ruconest; Pharming Group \& Salix Pharmaceuticals, Bridgewater, NJ) is a specific inhibitor of the classical complement activation pathway which is currently approved for treatment of hereditary angioedema. This $\mathrm{C} 1$ inhibitor (C1-INH) is under consideration as an open-label, multicenter pilot trial in adult patients with SARS-CoV-2 pneumonia ("PROTECTCOVID-19" trial).

In addition to the classical and alternative complement activation pathways, the lectin pathway provides another new promising avenue for pharmacological targeting in COVID-19.

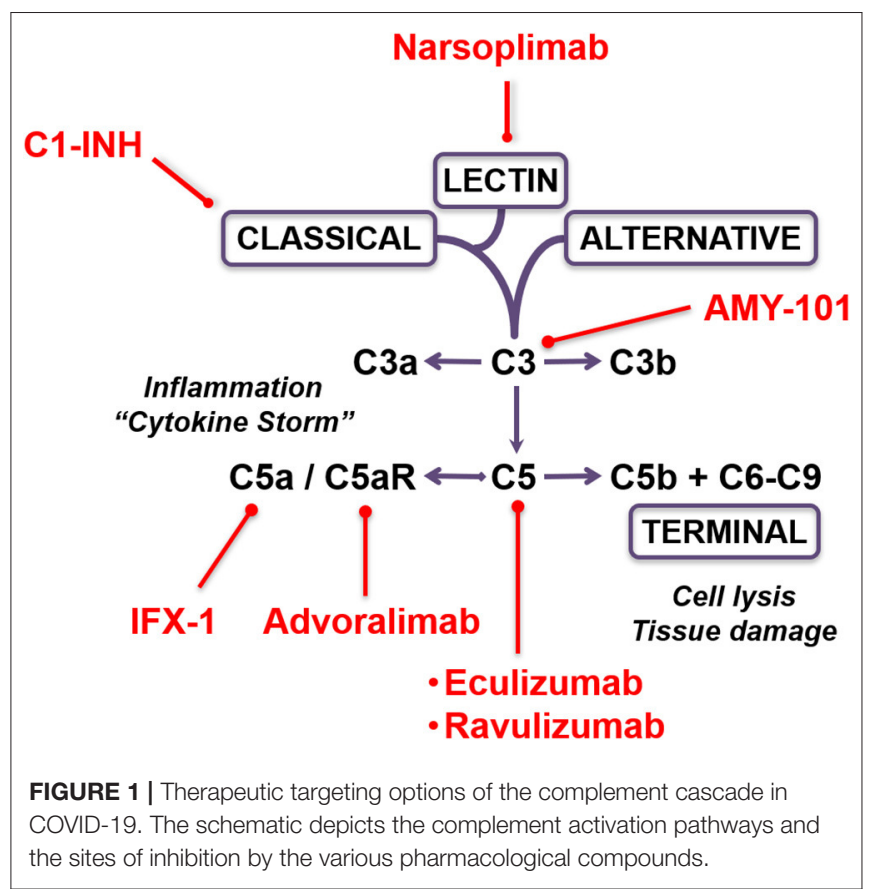

The complement lectin pathway is activated when a pattern recognition receptor, such as mannose binding lectin (MBL), binds to pathogen-associated molecular patterns expressed on the surface of invading microorganisms (29). The complement cascade is then initiated by $\mathrm{MBL}$ forming complexes with MBL-associated serine proteases 1 and 2 (MASP- 1 and MASP2 , respectively) in a similar fashion that $\mathrm{C} 1$ is activated through the classical pathway, leading to $\mathrm{C} 4$ and $\mathrm{C} 2$ cleavage and assembly of the C3 convertase (30). A historic casecontrol study on 569 SARS patients demonstrated a role of MBL gene polymorphisms in contributing to the susceptibility of viral invasion, and implied that the complement lectin pathway represents the "first line of defense" against SARS$\mathrm{CoV}$ infection $(31,32)$. This notion is supported by recent histopathological findings in patients with severe COVID-19, demonstrating the deposition of complement lectin pathway components MBL and MASP-2, as well as complement activation fragments $\mathrm{C} 4 \mathrm{~d}$ and $\mathrm{C} 5 \mathrm{~b}-9$, in the microvasculature of human lung tissue specimens with SARS-CoV-2 infection (21). Narsoplimab (OMS721; Omeros Corporation, Seattle, WA) is a novel human monoclonal antibody that targets MASP-2 and prevents lectin pathway-mediated inflammation and endothelial damage in a variety of autoimmune disorders (33). The safety and efficacy of narsoplimab is currently being investigated in a phase 2 dose-escalation cohort study in patients with complement-mediated hyperinflammatory conditions, including hematopoietic stem cell transplantation-associated thrombotic microangiopathy, thrombotic thrombocytopenic purpura, and atypical hemolytic uremic syndrome (33). Several other human complement inhibitors are currently in phase 2 or phase 3 clinical trials for different indications, raising the possibility that FDAapproved complement inhibitors will quickly join the developing 
arsenal of therapeutics for treatment of COVID-19 patients beyond compassionate use (34-36).

\section{SUMMARY}

In summary, the complex immune dysregulation observed in patients with severe COVID-19 remains poorly understood. The pharmacological targeting of complement activation in severe COVID-19 may attenuate the increased mortality observed in a younger cohort of patients with persistent hyperinflammation, thromboembolic complications, and cardiac arrest beyond terminal respiratory failure associated with SARS-CoV-2 pneumonia. Moving forward, it will be important to carefully monitor for beneficial and adverse

\section{REFERENCES}

1. Cao Y, Liu X, Xiong L, Cai K. Imaging and clinical features of patients with 2019 novel coronavirus SARS-CoV-2: a systematic review and meta-analysis. J Med Virol. (2020). doi: 10.1002/jmv.25822. [Epub ahead of print].

2. Zhou F, Yu T, Du R, Fan G, Liu Y, Liu Z, et al. Clinical course and risk factors for mortality of adult inpatients with COVID-19 in Wuhan, China: a retrospective cohort study. Lancet. (2020) 395:105462. doi: 10.1016/S0140-6736(20)30566-3

3. Yang X, Yu Y, Xu J, Shu H, Xia J, Liu H, et al. Clinical course and outcomes of critically ill patients with SAHRS-CoV-2 pneumonia in Wuhan, China: a single-centered, retrospective, observational study. Lancet Respir Med. (2020) 8:475-81. doi: 10.1016/S2213-2600(20)30079-5

4. Tian W, Jiang W, Yao J, Nicholson CJ, Li RH, Sigurslid HH, et al. Predictors of mortality in hospitalized COVID-19 patients: a systematic review and meta-analysis. J Med Virol. (2020). doi: 10.1002/jmv.26050. [Epub ahead of print].

5. Jose RJ, Manuel A. COVID-19 cytokine storm: the interplay between inflammation and coagulation. Lancet Respir. Med. (2020) 8:e46-7. doi: 10.1016/S2213-2600(20)30216-2

6. Centurión OA, Scavenius KE, García LB, Torales JM, Miño LM. Potential mechanisms of cardiac injury and common pathways of inflammation in patients with COVID-19. Crit Pathw Cardiol. (2020). doi: 10.1097/HPC.0000000000000227. [Epub ahead of print].

7. Riphagen S, Gomez X, Gonzalez-Martinez C, Wilkinson N, Theocharis P. Hyperinflammatory shock in children during COVID-19 pandemic. Lancet. (2020) 395:1607-8. doi: 10.1016/S0140-6736(20)31094-1

8. Soy M, Keser G, Atagündüz P, Tabak F, Atagündüz I, Kayhan S. Cytokine storm in COVID-19: pathogenesis and overview of antiinflammatory agents used in treatment. Clin Rheumatol. (2020) 39:208594. doi: 10.1007/s10067-020-05190-5

9. Gubernatorova EO, Gorshkova EA, Polinova AI, Drutskaya MS. IL-6: relevance for immunopathology of SARS-CoV-2. Cytokine Growth Factor Rev. (2020) 53:13-24. doi: 10.1016/j.cytogfr.2020.05.009

10. Toniati P, Piva S, Cattalini M, Garrafa E, Regola F, Castelli F, et al. Tocilizumab for the treatment of severe COVID-19 pneumonia with hyperinflammatory syndrome and acute respiratory failure: a single center study of 100 patients in Brescia, Italy. Autoimmun Rev. (2020) 19:102568. doi: 10.1016/j.autrev.2020.102568

11. Zhang S, Li L, Shen A, Chen Y, Qi Z. Rational use of tocilizumab in the treatment of novel coronavirus pneumonia. Clin Drug Investig. (2020) 40:5118. doi: 10.1007/s40261-020-00917-3

12. Hassoun A, Thottacherry ED, Muklewicz J, Aziz QU, Edwards J. Utilizing tocilizumab for the treatment of cytokine release syndrome in COVID-19. J Clin Virol. (2020) 128:104443. doi: 10.1016/j.jcv.2020.104443

13. Salvi R, Patankar P. Emerging pharmacotherapies for COVID-19. Biomed Pharmacother. (2020) 128:110267. doi: 10.1016/j.biopha.2020.110267 effects associated with therapeutic complement inhibition (36). In addition, well-designed clinical studies are needed to determine patient outcomes by inhibiting complement in isolation vs. a combination therapy by targeting other key mediators responsible for the "cytokine storm" (37). Finally, from a patient safety perspective, we will have to determine the extent of retained innate immunity required for viral clearance and prevention of secondary bacterial infections.

\section{AUTHOR CONTRIBUTIONS}

Both authors conceived the concept of this article and wrote the manuscript together.

14. Lythgoe MP, Middleton P. Ongoing clinical trials for the management of the COVID-19 pandemic. Trends Pharmacol Sci. (2020) 41:36382. doi: 10.1016/j.tips.2020.03.006

15. Thomas G, Frederick E, Hausburg M, Goldberg L, Hoke M, Roshon M, et al. The novel immunomodulatory biologic LMWF5A for pharmacological attenuation of the "cytokine storm" in COVID-19 patients: a hypothesis. Patient Saf Surg. (2020) 14:21. doi: 10.1186/s13037-020-00248-4

16. Stahel PF, Barnum SR. The role of the complement system in CNS inflammatory diseases. Expert Rev Clin Immunol. (2006) 2:445-56. doi: 10.1586/1744666X.2.3.445

17. Barnum SR. Complement: a primer for the coming therapeutic revolution. Pharmacol Ther. (2017) 172:63-72. doi: 10.1016/j.pharmthera.2016.11.014

18. Gralinski LE, Sheahan TP, Morrison TE, Menachery VD, Jensen K, Leist SR, et al. Complement activation contributes to severe acute respiratory syndrome coronavirus pathogenesis. mBio. (2018) 9:e0175318. doi: 10.1128/mBio.01753-18

19. Wang R, Xiao H, Guo R, Li Y, Shen B. The role of C5a in acute lung injury induced by highly pathogenic viral infections. Emer. Microbes Infect. (2015) 4:e28. doi: 10.1038/emi.2015.28

20. Jiang Y, Zhao G, Song N, Li P, Chen Y, Guo Y, et al. Blockade of the C5a-C5aR axis alleviates lung damage in hDPP4-transgenic mice infected with MERSCoV. Emerg Microbes Infect. (2018) 7:77. doi: 10.1038/s41426-018-0063-8

21. Magro C, Mulvey JJ, Berlin D, Nuovo G, Salvatore S, Harp J, et al. Complement associated microvascular injury and thrombosis in the pathogenesis of severe COVID-19 infection: a report of five cases. Transl Res. (2020) 13. doi: 10.1016/j.trsl.2020.04.007

22. Campbell CM, Kahwash R. Will complement inhibition be the new target in treating COVID-19 related systemic thrombosis? Circulation. (2020) 141:1739-41. doi: 10.1161/CIRCULATIONAHA.120.047419

23. Ricklin D, Mastellos DC, Lambris JD. Therapeutic targeting of the complement system. Nat Rev Drug Discov. (2019). doi: 10.1038/s41573-019-0055-y

24. Mastellos DC, Ricklin D, Lambris JD. Clinical promise of nextgeneration complement therapeutics. Nat Rev Drug Discov. (2019) 18:707-29. doi: 10.1038/s41573-019-0031-6

25. Mastaglio S, Ruggeri A, Risitano AM, Angelillo P, Yancopoulou D, Mastellos DC, et al. The first case of COVID-19 treated with the complement C3 inhibitor AMY-101. Clin Immunol. (2020) 215:108450. doi: 10.1016/j.clim.2020.108450

26. Diurno F, Numis FG, Porta G, Cirillo F, Maddaluno S, Ragozzino A, et al. Eculizumab treatment in patients with COVID-19: preliminary results from real life ASL Napoli 2 Nord experience. Eur Rev Med Pharmacol Sci. (2020) 24:4040-7. doi: 10.26355/eurrev_202004_20875

27. Risitano AM, Mastellos DC, Huber-Lang M, Yancopoulou D, Garlanda C, Ciceri F, Lambris JD. Complement as a target in COVID19? Nat Rev Immunol. (2020) 20:343-4. doi: 10.1038/s41577-0200366-6 
28. Cugno M, Meroni PL, Gualtierotti R, Griffini S, Grovetti E, Torri A, et al. Complement activation in patients with COVID-19: a novel therapeutic target. J Allergy Clin Immunol. (2020). doi: 10.1016/j.jaci.2020. 05.006. [Epub ahead of print].

29. Beltrame MH, Catarino SJ, Goeldner I, Boldt AB, de Messias-Reason IJ. The lectin pathway of complement and rheumatic heart disease. Front Pediatr. (2015) 2:148. doi: 10.3389/fped.2014.00148

30. LaFon DC, Thiel S, Kim YI, Dransfield MT, Nahm MH. Classical and lectin complement pathways and markers of inflammation for investigation of susceptibility to infections among healthy older adults. Immun Ageing. (2020) 17:18. doi: 10.1186/s12979-020-00189-7

31. Ip WK, Chan KH, Law HK, Tso GH, Kong EK, Wong WH, et al. Mannosebinding lectin in severe acute respiratory syndrome coronavirus infection. $J$ Infect Dis. (2005) 191:1697-704. doi: 10.1086/429631

32. Zhang H, Zhou G, Zhi L, Yang H, Zhai Y, Dong X, et al. Association between mannose-binding lectin gene polymorphisms and susceptibility to severe acute respiratory syndrome coronavirus infection. J Infect Dis. (2005) 192:1355-61. doi: 10.1086/491479

33. Kaplon H, Muralidharan M, Schneider Z, Reichert JM. Antibodies to watch in 2020. MAbs. (2020) 12:1703531. doi: 10.1080/19420862.2019.1703531

34. Maglakelidze N, Manto KM, Craig TJ. A review: does complement or the contact system have a role in protection or pathogenesis of COVID-19? Pulm Ther. (2020). doi: 10.1007/s41030-020-00118-5. [Epub ahead of print].

35. Noris M, Benigni A, Remuzzi G. The case of Complement activation in COVID-19 multiorgan impact. Kidney Int. (2020). doi: 10.1016/j.kint.2020.05.013. [Epub ahead of print].
36. Barnum SR. Therapeutic inhibition of complement: well worth the risk Trends Pharmacol Sci. (2017) 38:503-5. doi: 10.1016/j.tips.2017.03.009

37. Mahmudpour M, Roozbeh J, Keshavarz M, Farrokhi S, Nabipour I. COVID-19 cytokine storm: the anger of inflammation. Cytokine. (2020) 133:155151. doi: 10.1016/j.cyto.2020.155151

Conflict of Interest: PS has a United States Patent No. 11,441,828 entitled: "Inhibition of the alternative complement pathway for treatment of traumatic brain injury, spinal cord injury, and related conditions." PS is employed by HCA Healthcare as the chief medical officer at the Medical Center of Aurora. SB has a United States Patent \# 10,535,004 "Methods and compositions for diagnosis and treatment of meningitis." SB is employed by CNine Biosolutions LLC, a company involved in developing complement diagnostic assays.

The authors declare that the research was conducted in the absence of any other commercial or financial relationships that could be construed as a potential conflict of interest. Specifically, there is no conflict of interest whatsoever by either of the two authors related to the pharmacological agents and companies cited in this manuscript.

Copyright (C) 2020 Stahel and Barnum. This is an open-access article distributed under the terms of the Creative Commons Attribution License (CC BY). The use, distribution or reproduction in other forums is permitted, provided the original author(s) and the copyright owner(s) are credited and that the original publication in this journal is cited, in accordance with accepted academic practice. No use, distribution or reproduction is permitted which does not comply with these terms. 